ISSN: 0213-3563

https://doi.org/10.14201/azafea202022167192

\title{
EMERGENCIA DEL INSTITUCIONALISMO EN LA TEORÍA ARGUMENTAL
}

\author{
Emergence of Institutionalism in Argumentation Theory
}

María G. NAVARro

Universidad de Salamanca

Recibido: 4 de agosto de 2019

Aceptado: 22 de julio de 2020

\section{RESUMEN}

Uno de los desafíos relacionados con las prácticas discursivas de agentes argumentativos es el de llegar a conocer si esas interacciones tienen un efecto institucional. En este artículo se sostiene que en el nuevo institucionalismo se perfilan enfoques teóricos y análisis determinantes para investigar prácticas argumentativas que tienen lugar en procesos de legitimación y reconocimiento. Aquí se defiende un doble enfoque socio-institucional y discursivo o constructivista de la teoría argumental, y se sostiene que dicha perspectiva podría ampliarse hasta dar lugar a un programa de investigación destinado a interpretar procesos argumentativos en la esfera pública que actúan como mecanismo de cálculo y conformación de capital social.

Palabras clave: argumentación; comportamiento argumentativo; institucionalismo; capital social; teoría pragma-dialéctica de la argumentación; lógica civil.

\section{ABSTRACT}

One of the challenges related to the discursive practices of argumentative agents is to get to know if those interactions have an institutional effect. In this article, it is argued that in the new institutionalism, theoretical approaches and deterministic analysis are outlined to investigate argumentative practices that take place in processes of legitimation and recognition. Here a double socio-institutional and discursive or constructivist approach 
to the argumentation theory is defended, and it is argued that this perspective could be extended to a research program aimed at interpreting argumentative processes in the public sphere that act as calculation mechanism and conformation of social capital.

Key words: argumentation; argumentative behaviour; institutionalism; social capital; pragma-dialectical theory of argumentation; civil logic.

\section{ANTECEDENTES Y SENTIDO DEL INSTITUCIONALISMO EN ESTRATEGIAS DISCURSIVAS}

Las estrategias discursivas se adaptan a un conjunto de condiciones institucionales preexistentes. Esta fue una de las tesis defendidas por el holandés Frans van Eemeren (2010) en su obra Strategic Maneuvering in Argumentative Discourse. Extending the Pragma-dialectical Theory of Argumentation ${ }^{1}$. En esta obra, el fundador de la denominada Escuela de argumentación de la Universidad de Ámsterdam (también conocida como "Escuela de Ámsterdam”) defendió que el término 'argumentación' no solo hace referencia a un concepto teórico sobre el que se teoriza en modelos analíticos (e. g. el modelo ideal de una discusión crítica) $)^{2}$. El término 'argumentación' se refiere también, y, en primer lugar, a un fenómeno empírico que puede ser observado en

1. En la obra de van Eemeren, la noción 'strategic maneuvering' («maniobra estratégica») sirve al objetivo de explicar la razón de ser del poder persuasivo del argumentar falaz. De acuerdo a su concepción pragma-dialéctica de la argumentación, las falacias constituyen violaciones de las reglas que deben seguirse para conducir toda discusión crítica hacia la resolución de aquellas diferencias de opinión de fondo de las que, precisamente, surge como respuesta o en anticipación la práctica de argumentar. Una buena introducción y análisis coral llevado a cabo por importantes colaboradores e integrantes de la Escuela de Ámsterdam acerca del impacto que tuvo una de las obras más influyentes de van Eemeren (a saber: la que fuera su tesis doctoral redactada en holandés, traducida al inglés y publicada dos años después en colaboración con su coautor, Rob Grootendorst, bajo el titulo Speech Acts in Argumentative Discussions. A Theoretical Model of the Analysis of Discussions Directed towards Solving Conflicts of Opinion) sobre una publicación posterior es Strategic Strategic Maneuvering in Argumentative Discourse, puede consultarse en Garssen (2010,13-21).

2. Van Eemeren y Grootendorst (1982) defendieron en su tesis doctoral que existe un código de conducta para la resolución crítica de las discusiones. En una obra posterior, los autores enumeraron hasta diez reglas básicas instrumentales para resolver toda disputa entre un proponente y un oponente cuando estos defienden un punto de vista en el curso de un litigio (van Eemeren y Grootendorst 1987). La argumentación falaz es 
una multitud de prácticas comunicativas reconocidas por los argumentadores. La argumentación no es solo una estructura de derivaciones lógicas, actitudes psicológicas o creencias epistémicas, también es un conjunto de actos de habla con una función comunicativa concreta en un contexto discursivo específico. Si las prácticas comunicativas se pueden, de hecho, reconocer es porque están conectadas con tipos específicos de contextos institucionales en los que estas desempeñan ciertos propósitos relevantes para la realización del objetivo o meta institucional en cuestión. Por ese motivo, estas prácticas discursivas se convencionalizan de acuerdo con distintos tipos de requisitos. El investigador holandés extrajo de ello una tesis fuerte (en adelante, T1) que nos advierte de la existencia de precondiciones institucionales:

T1 - Las posibilidades de maniobrar estratégicamente en el discurso argumentativo están determinadas por las precondiciones institucionales que prevalecen en la práctica comunicativa en cuestión.

En esa misma obra, van Eemeren menciona en una nota a pie de página -aparentemente marginal, pero de una importancia radical, como se habrá de ver- una hipótesis de investigación nuclear (en adelante, H1):

H1 - Se podrían llegar a explicar los orígenes de las instituciones a partir de los efectos derivados de su existencia.

De acuerdo con van Eemeren, esta hipótesis de investigación conecta con el institucionalismo de elección racional ${ }^{3}$. De hecho, el propio autor añade

aquel modo de argumentar que viola alguna de las reglas pragma-diálecticas de la discusión crítica que ellos defienden.

3. De acuerdo con el enfoque del institucionalismo de elección racional, y conforme a la perspectiva de North (1990), los actores optimizan beneficios a través de su comportamiento en función de sus preferencias debido a la existencia de una estructura imperante de incentivos. Es lógico que van Eemeren declarase una mayor afinidad con esta perspectiva dentro del más amplio conjunto de teorías que conforman lo que denominamos institucionalismo o teoría institucional de acuerdo con la cual no solo es susceptible de análisis el impacto de los cambios de la racionalidad en las identidades individuales sino en las organizacionales. Y ello es así porque las instituciones económicas (en analogía con las pretensiones de institucionalizar la práctica argumentativa de acuerdo con su teoría pragma-dialéctica) son entendidas como las reglas del juego en una sociedad toda vez que estas aportan, entre otras cosas, las limitaciones formales e informales que modulan la interacción humana. Así como van Eemeren y Grootendorst aportaron una lista de diez reglas para la resolución crítica de una discusión, este modelo del institucionalismo sos- 
que, al igual que los defensores del institucionalismo de elección racional (Coase 1937; North 1990; Williamson 1985, entre otros), él también prefiere hacer hincapié en la relativa autonomía de las instituciones políticas y en la importancia de su acción simbólica. Hay varios pasajes en la obra de van Eemeren que podrían referirse para sustentar lo anterior. Me referiré aquí a dos paisajes breves:

Yo uso los términos "institución", "institucional" e "institucionalizado" en un sentido muy amplio, por lo que no sólo se refieren a las organizaciones formalmente establecidas de la ley, la administración y las escueles, y mucho menos sólo a las cárceles, clínicas psiquiátricas y el ejército, sino a todos los macro-contextos social y culturalmente establecidos, con independencia de si son parte de la esfera personal, técnica o pública, en la que se desarrollan ciertas prácticas comunicativas convencionalizadas (formal o informalmente), incluyendo, por ejemplo, los macro-contextos de comercio, espectáculos públicos y las relaciones interpersonales. (van Eemeren 2012, pp. 209-10).

Tal y como queda de manifiesto en esta breve cita y, sobre todo, en el resto de la obra del investigador holandés, su concepción de la pragma-dialéctica se desarrolló atendiendo a la influencia del nuevo institucionalismo. Respecto a este enfoque de la ciencia política, apunta más adelante que sintoniza con el enfoque de la teoría de la elección racional. Pero si van Eemeren consideró necesario hacer esta aclaración en una nota a pie de página es porque previamente había afirmado que, al intentar describir las maneras en que se convencionalizan las prácticas comunicativas, su punto de partida es que toda práctica comunicativa pude ser reconocida como tal es porque presenta «un cierto grado de convencionalización que es dependiente del fundamento institucional -el objetivo institucional- de la práctica comunicativa en cuestión.» (van Eemeren 2012, p. 212). Y, a continuación, alude al enfoque teórico que tiene presente al escribir tal afirmación, que no es otro que el importante paradigma del nuevo institucionalismo que irrumpió en la ciencia política anglosajona, y cuya influencia se mantiene presente a lo largo de toda la obra del fundador de la teoría pragma-dialéctica de la argumentación.

tuvo que los actores disponen de información completa en procesos de toma de decisiones. Por así decir, no se hizo esperar la afinidad electiva entre la teoría pragma-dialéctica de la argumentación e institucionalismo de elección racional. 
EN LA TEORÍA ARGUMENTAL

Yo creo que mi enfoque se conecta con el "institucionalismo de elección racional”, como se practica en ciencias políticas, economía, antropología y sociología dentro del Nuevo Institucionalismo. En el tratamiento de la cuestión de cómo interpretar la relación entre las instituciones y el comportamiento, el Nuevo Institucionalismo hace hincapié en la relativa autonomía de las instituciones políticas y la importancia de la acción simbólica (March y Olsen, 1984: p. 734). De acuerdo con Hall y Taylor, el institucionalismo de elección racional nos llama la atención sobre "el papel que la interacción estratégica entre los actores desempeña en la determinación de los resultados políticos (1996: p. 951). Por lo general, este enfoque es “funcionalista” en el sentido de explicar los orígenes de una institución, en gran medida, en términos de los efectos que se derivan de su existencia, y también “intencionalista”, en el sentido de asumir que el proceso de creación institucional es deliberado, mientras que su análisis es "voluntarista", en el sentido que tienden a considerar la creación institucional como un proceso cuasi-contractual marcado por el acuerdo voluntario entre los actores relativamente iguales e independientes (Hall y Taylor, 1996: p. 952). (van Eemeren 2012, pp. 212).

En cierto modo, puede decirse que van Eemeren asume H1 como un corolario de T1 y ello por dos razones: (1) porque el autor utiliza un verbo en condicional cuando afirma se podrian llegar a explicar los orígenes de las instituciones a partir de los efectos derivados de su existencia y (2) porque presenta dicha proposición como si no necesitase una demostración particular. Por consiguiente, conforme a nuestra interpretación de $\mathrm{H} 1$, la fórmula empleada por van Eemeren en dicha obra corresponde en verdad a un corolario que, si tenemos presente el sentido general de la misma, bien podría expresarse en los siguientes términos:

Corolario-La práctica comunicativa de argumentar, y de argumentar estratégicamente, no solo está determinada por precondiciones institucionales, sino que dicha práctica es un efecto derivado de la existencia de dichas constricciones institucionales.

Este Corolario no invita a considerar las reglas pragmáticas de actuación presentes en la teoría pragma-dialéctica de la argumentación como si su articulación normativa estuviera constreñida por el efecto de instituciones particulares ${ }^{4}$. Tan solo se hace eco de que la argumentación estratégica y los

4. Precisamente, lo que aporta van Eemeren es una teoría argumental fuertemente articulada desde el punto de vista normativo con el propósito de influir sobre los procesos de convencionalización de la práctica comunicativa de índole argumentativa, informando 
procesos de convencionalización de las prácticas comunicativas son dependientes del fundamento institucional -el objetivo institucional- de la práctica comunicativa en cuestión. Si se llama la atención aquí sobre este Corolario es porque las siguientes razones avalan esta interpretación: van Eemeren utilizó un verbo en condicional porque asumía que para demostrar la validez de la hipótesis presentada habría que llevar a cabo una investigación empírica delimitando prácticas y entornos institucionales específicos con el propósito de hallar las evidencias necesarias para poder elaborar argumentos que respaldaran H1. Al mismo tiempo, sostener que los efectos derivados de la existencia de instituciones pueden llegar a informarnos acerca de los orígenes de determinadas instituciones es parte de un programa de investigación que ha tenido presente en su obra pues el autor asume que la argumentación es, a un tiempo, parte de una práctica institucional compleja y efecto derivado de su sola existencia. Sin embargo, no deja de ser revelador que $\mathrm{H} 1$ pueda asumirse como un Corolario pues, si damos por buenas las razones anteriores, ello indicaría que su autor asume que toda teoría argumental es en el fondo una investigación acerca de los orígenes de la conformación y desarrollo de las instituciones, de ahí que este no puede por menos que centrarse en sus efectos, esto es, en las prácticas argumentales. De donde se infiere que cualquier especialista en teoría argumental asume implícitamente una determinada concepción acerca del significado y sentido de la existencia de instituciones. Esto es lo que llevó a van Eemeren a añadir de inmediato la nota a pie de página a la que he aludido, pues era de todo punto necesario hacer explícito en ese punto con qué orientación del institucionalismo asociaba sus propuestas en el campo argumental. No obstante, si bien la nota era marginal pues con ella su autor solo manifestaba que su campo de investigación sintonizaba con el institucionalismo de elección racional, su emergencia era de una extraordinaria importancia. En $\mathrm{H} 1$ van Eemeren hace notar un destacado bien que está implícito en el Corolario, a saber, el de que la teoría argumental podría asumirse como un campo derivado y dependiente de la teoría de las instituciones. En estas páginas se aludirá a otras recientes formas de emergencia del institucionalismo en la teoría argumental que no han tenido lugar en la

así sobre el objetivo institucional y dando lugar a una Escuela de Argumentación que puede de hecho exhibir con razón su vocación institucional pues la práctica argumental de diferentes dominios profesionales (e. g. médico, periodístico, publicitario, parlamentario o político, etc.) puede y debería, con razón, remitir a un fundamento institucional, el de los amplios desarrollos del discurso o la lógica civil propugnados por la teoría pragma-dialéctica de la argumentación. 
Escuela de Ámsterdam sino entre filósofos y académicos hispanohablantes entre quienes se incluye quien esto escribe.

Entre los especialistas en el campo de la «teoría argumental»-como gustaba en referirse a este campo el filósofo español Quintín Racionero (2000a, 2000b, 2009, 2010a, 2010b)- existen tres perspectivas para analizar cualquier episodio de comunicación humana en el que se pueda comprobar el uso de argumentos. Esas perspectivas son la lógica (que analiza los productos de la argumentación), la dialéctica (que analiza los procedimientos argumentativos) y la retórica (que trata de los procesos argumentativos en un sentido amplio). Tres archiconocidas perspectivas que aportan, desde el punto de vista filosófico, lo que Racionero dio en llamar "perspectiva de naturalización para el análisis de la racionalidad en su conjunto» toda vez que dichos enfoques facilitan al especialista el análisis de las conductas racionales y le informan acerca de las que no lo son. La perspectiva de naturalización en el análisis de la racionalidad-que ciertamente consigue plasmarse en enfoques propios de la retórica, la dialéctica o la lógica- puede expresarse en términos aún más comprehensivos si utilizamos para ello la distinción que esbozó Racionero para dar respuesta a la encuesta «El estado actual de los estudios sobre Argumentación» (Bermejo 2010). Racionero quiso en su respuesta distinguir e informar -somera bien que contundentemente- acerca de las tres grandes aproximaciones o perspectivas de naturalización de la racionalidad. La primera de ellas la identificó con el estudio de la construcción e intercambio sociales del sentido (i.e. Pragmática); la segunda la relacionó con el análisis de los enfoques sistémicos que, haciendo uso de signos, producen discursos diferenciados (i.e. Semiología); e identificó la tercera perspectiva con la Hermenéutica, entendida como «la interpretación de los mensajes de acuerdo con los archivos generados por la memoria histórica.» (Racionero 2010, 30). En la concepción de la teoría argumental de dicho autor difícilmente sería necesario alumbrar una perspectiva socio-institucional pues va de suyo que el filósofo advirtió en su punto de partida-como teórico de la argumentación y gran conocedor de la Retórica- que no se podía identificar el análisis de los argumentos con ningún modelo de lógica formal y/o de lógica informal. Para quien defendió que el sentido de las modelizaciones de la lógica está claramente determinado por los fines que proponentes y oponentes buscan a su través (e.g. efectuar demostraciones, mostrar la razonabilidad de un argumento, conseguir persuadir, probar la conveniencia de algo, etc.) no podía ser más que un punto de partida y una evidencia que, en toda teoría argumental, debe reconocerse una perspectiva civil de la lógica. 
MARÍA G. NAVARRO

EMERGENCIA DEL INSTITUCIONALISMO

EN LA TEORÍA ARGUMENTAL

TABLA 1. El institucionalismo de elección racional

\begin{tabular}{|c|c|c|c|}
\hline Problemas & $\begin{array}{l}\text { Ejemplos de } \\
\text { instituciones }\end{array}$ & Capital asociado & Autores/as \\
\hline $\begin{array}{l}\text { Fallos de los } \\
\text { mercados reales, } \\
\text { costes de transac- } \\
\text { ciones (e. g. de } \\
\text { información, ne- } \\
\text { gociación, investi- } \\
\text { gación, etc.). }\end{array}$ & $\begin{array}{l}\text { Empresas, leyes } \\
\text { económicas, } \\
\text { derechos de } \\
\text { propiedad, ins- } \\
\text { tituciones infor- } \\
\text { males, etc. }\end{array}$ & $\begin{array}{l}\text { Capital económi- } \\
\text { co: actúa como un } \\
\text { mecanismo de cál- } \\
\text { culo de capitales } \\
\text { informativos, de } \\
\text { negociación, in- } \\
\text { vestigación, etc. }\end{array}$ & $\begin{array}{l}\text { Douglass C. North } \\
\text { Jack Knight } \\
\text { Harold Demsetz } \\
\text { Terry M. Moe } \\
\text { Oliver E. William- } \\
\text { son } \\
\text { Vivien Lowndes }\end{array}$ \\
\hline
\end{tabular}

Fuente: Elaboración propia a partir de Vergara (1997), Mackay et al. (2010), Aguiar (2014).

No obstante, algunos especialistas del campo de la teoría argumental han propuesto recientemente ampliar las tres perspectivas clásicas para añadir una nueva; a saber: la perspectiva socio-institucional. De las primeras páginas de este artículo se desprende que asumo que la perspectiva socio-institucional ya fue tenida en cuenta por el propio van Eemeren (2010) cuando este sostuvo que, a través de los efectos derivados de la existencia de precondiciones institucionales (la propia práctica argumentativa constituye uno de esos efectos), se pueden investigar las instituciones políticas, así como los efectos de su acción simbólica. No obstante, el investigador holandés, más allá de proyectar su teoría pragma-dialéctica sobre los diversos dominios de prácticas argumentativas para promover una sociedad abierta y democrática, no se propuso sin embargo ampliar la cuarta perspectiva o perspectiva socioinstitucional ${ }^{5}$. Este ha sido precisamente uno de los objetivos de investiga-

5. A pesar de ello, es de justicia recordar los cuatro componentes o puntos de partida metateóricos que inspiran la teoría pragma-dialéctica de la argumentación entre los cuales destaca la socialización. Los actos de habla argumentativos no tienen lugar en el vacío pues tienen la función de socializar, es decir, que la argumentación debe entenderse como un proceso interactivo entre dos o más hablantes, y nunca como el producto del razonamiento de uno solo. Y debe añadirse que los otros tres puntos de partida metateóricos asumidos por van Eemeren comparten un fuerte compromiso social o socializador. Así, el objetivo de la funcionalización se cumple cuando se tratan esas porciones de discurso argumentativo como elementos que sirven para conducir eventos de habla de la vida real y no como inferencias lógicas aisladas. El objetivo de la externalización se cumple cuando se consigue evidenciar todo aquello con lo que proponente u oponente se comprometen, evitando así al auditorio el trabajo de adivinar sus motivaciones. Y, por último, el objetivo de la dialectificación se logra cuando se trata la argumentación como 
ción de Luis Vega, quien relaciona esta importante cuarta perspectiva socioinstitucional con la denominada «lógica civil» o «lógica del discurso civil», en clara alusión -según confiesa su promotor-a la tradición retórica hispanohablante de atención al discurrir común de los asuntos públicos o de orden práctico -entre los que suele tener presente a Baltasar Gracián, Pedro Simón Abril, Gregorio Mayàns, Carlos Vaz Ferreira, Luis Recasens o Andrés Piquer, entre otros-. La introducción de la perspectiva socio-institucional en el campo de la teoría argumental es una de las contribuciones más importantes de Vega $(2004,2008,2012,2013$ a, 2013b, 2016). Algunos autores han resaltado el carácter programático de su aportación y han subrayado la relevancia de su perspectiva socio-institucional (Marraud 2015). La denominada por Vega «lógica civil» analiza fenómenos del discurso en la esfera pública que ni se capturan ni se comprenden plenamente con ayuda de herramientas de análisis características de la lógica, la dialéctica o la retórica. El cometido de evaluar la calidad del ejercicio público de la razón es de difícil ejecución si esta se asume como efecto de un tipo de procedimiento dialéctico, un proceso retórico específico y/o un producto efectuado de la lógica. Por ese motivo, parece razonable afirmar que si la perspectiva socio-institucional debe añadirse y diferenciarse de las tres clásicas perspectivas (i.e. dialéctica, retórica y lógica) es porque su objeto de estudio radica en fenómenos cuyo dinamismo y complejidad solo se despliegan en la esfera social y política. Una esfera sobre la que ya van Eemeren advirtió su importante acción simbólica. La perspectiva socio-institucional podría desarrollarse hasta dar lugar a un programa (o varios, en plural) ciertamente innovador. En términos generales, puede afirmarse que hay diferentes rasgos que caracterizan al enfoque socioinstitucional en cuanto tal:

(i) análisis e interpretación de las creencias, los valores, las actitudes, etc. que dotan de sentido a los intercambios argumentativos;

(ii) profundización en cuestiones como el importante papel de los compromisos compartidos en toda comunicación intersubjetiva;

(iii) indagación en los procesos de inducción de creencias;

(iv) informa, en definitiva, acerca de los criterios que determinan la calidad del discurso público.

No obstante, y a pesar de la importancia de los rasgos con los que se puede describir el enfoque socio-institucional, en estas páginas voy a sostener

un medio racional para convencer a un oponente crítico, y no como un simple acto de persuasión. 
dos argumentos generales para mostrar que dicha innovadora perspectiva se puede ampliar hasta alcanzar un ámbito de investigación alternativo que, si bien aparece mencionado en el nombre del enfoque, en verdad lo hace en cuanto lema, pues no se ha llegado a desarrollar en cuanto tal un modelo de institucionalismo o nuevo institucionalismo desde el campo argumental ${ }^{6}$. Con ese objetivo, identifico en primer lugar un rasgo aún más elemental con el que debería vincularse programáticamente este enfoque. El fenómeno de la argumentación es un ingrediente fundamental de diversas prácticas, que tiene lugar en el espacio público y que está ligado a procesos sociales, políticos, epistémicos, retóricos, económicos, etc. de legitimación y reconocimiento. La investigación acerca de estos dos procesos (e. g. los procesos mediante los cuales se produce legitimación y se obtiene reconocimiento) resulta fundamental para ampliar el espacio de oportunidad teórico-práctico de la lógica del discurso civil entendida como un programa de investigación. Marraud (2015) sostiene que la perspectiva socio-institucional constituye un programa de investigación que ofrece soluciones al menos a dos problemas: (1) el uso de propuestas (y también de supuestos) tiene un encaje óptimo en el enfoque socio-institucional; y (2) el paradigma socio-institucional proporciona un marco teórico para teorías de las virtudes aplicadas al estudio de la argumentación. Sin embargo, los especialistas no han dedicado aún suficiente atención al análisis de los procesos de producción de legitimidad y reconocimiento desde la perspectiva del nuevo institucionalismo sociológico aplicado al campo argumental. Los modelos explicativos del nuevo institucionalismo en sus distintas formulaciones y tendencias son bien distintos, si bien existen elementos de convergencia entre ellos, y puntos en común. Por ejemplo, los institucionalistas históricos analizan las configuraciones organizacionales,

6. Ya Vega (2013) aludía a que argumentar una innovación implica «hacer la propuesta pertinente de modo razonable en orden a su reconocimiento y admisión.» En este artículo de 2013, en el que suponía nociones comunes de argumentación e innovación, se refería de manera tangencial a los procesos de reconocimiento y admisión, pues son ellos los que avalan la repercusión social de la invención. Estos dos aspectos, a saber: el reconocimiento y la admisión, que Vega asocia al mundo de la innovación y la invención, tienen en verdad mucho más que ver con la argumentación -si de verdad se asume el enfoque social e histórico de un institucionalismo aplicado al campo argumental- que la definición que ofrece de la práctica argumentativa como un proceso mediante el cual se da cuenta y razón de algo a alguien para lograr su conformidad (aunque Vega emplea el término «asentimiento»). 
EN LA TEORÍA ARGUMENTAL

centrando su atención en las coyunturas críticas y los procesos contemplados a largo plazo.

\section{TABLA 2. El nuevo institucionalismo histórico}

\begin{tabular}{|c|c|c|c|}
\hline Problemas & $\begin{array}{c}\text { Ejemplos } \\
\text { de instituciones }\end{array}$ & Capital asociado & Autores/as \\
\hline $\begin{array}{l}\text { Análisis de las ins- } \\
\text { tituciones a través } \\
\text { de sus legados, } \\
\text { eventos, secuen- } \\
\text { cias, continuidades } \\
\text { y trayectoria de } \\
\text { dependencia. }\end{array}$ & $\begin{array}{l}\text { Instituciones con } \\
\text { legados históricos } \\
\text { como parlamen- } \\
\text { tos, congresos, } \\
\text { senados, partidos } \\
\text { políticos, etc. }\end{array}$ & $\begin{array}{l}\text { Capital estraté- } \\
\text { gico: aunque las } \\
\text { instituciones limi- } \\
\text { tan a los actores, } \\
\text { estos llevan a cabo } \\
\text { estrategias delibe- } \\
\text { radas de conflicto } \\
\text { político y elección } \\
\text { racional. }\end{array}$ & $\begin{array}{l}\text { Kathleen Thelen } \\
\text { Peter A. Hall } \\
\text { Paul Pierson } \\
\text { Sven Steinno }\end{array}$ \\
\hline
\end{tabular}

Fuente: Elaboración propia a partir de Vergara (1997), Mackay et al. (2010), Aguiar (2014).

El punto de encuentro entre ambos institucionalismos no es otro que la idea de que las relaciones causales entre acontecimientos y fenómenos sociales no pueden apoyarse únicamente en la existencia de correlaciones entre dos variables. Por el contrario, dichas relaciones se basan en una teoría que demuestre precisamente que hay razones que justifican que dicha correlación debe existir, en virtud de una teoría acerca de la causalidad social observada. En este ámbito, no son únicamente los procesos de toma de decisiones o las preferencias lo que debe llamar la atención del investigador social o del historiador, pues los procedimientos para la toma de decisiones (produzcan o no resultados estables) entran en este punto con todo derecho en el dominio de la teoría argumental. Tanto las decisiones como sus efectos prácticos solo pueden comprenderse en virtud de una teoría que verse e interprete precisamente las relaciones de causalidad que median entre ambas. Y, a su vez, dicha teoría en cuanto tal implica de lleno al campo argumental y, por tanto, a la práctica de dar y pedir razones. Para constatar la validez de esta perspectiva, a saber, la de que el institucionalismo no guarda únicamente relación con las preferencias sino con los actos de habla a un tiempo directivos y comisivos que denominamos «propuestas», basta tener presente el hecho de que, entre los investigadores sociales, el análisis de encuestas no es el único método empleado para comprender patrones individuales y/o colectivos. Las encuestas 
basadas en datos extraídos en un momento particular en torno a actitudes y comportamientos $^{7}$-de los que existe registro, pues su finalidad no es otra que la de obtener información a través de procedimientos sistemáticos tales como la aplicación de un cuestionario estandarizado a una muestra diseñada para que sea representativa-, pueden sin duda completarse con métodos como las entrevistas en profundidad porque solo estas permiten al investigador atender a lo que Racionero (1998) denominó «el ritmo del discurso» .

TABla 3. El nuevo institucionalismo social o sociológico

\begin{tabular}{|c|c|c|c|}
\hline Problemas & $\begin{array}{c}\text { Ejemplos de ins- } \\
\text { tituciones }\end{array}$ & $\begin{array}{c}\text { Capital } \\
\text { asociado }\end{array}$ & Autores/as \\
\hline $\begin{array}{l}\text { Dilemas sociales } \\
\text { y problemas de } \\
\text { coordinación. En- } \\
\text { fatiza los aspectos } \\
\text { de la cognición } \\
\text { social en lugar de } \\
\text { los estructurales. }\end{array}$ & $\begin{array}{l}\text { Normas sociales, } \\
\text { rituales, conven- } \\
\text { ciones, costum- } \\
\text { bres, movimientos } \\
\text { sociales, partidos } \\
\text { políticos, etc. }\end{array}$ & $\begin{array}{l}\text { Capital social: po- } \\
\text { tencia la racionali- } \\
\text { dad colectiva; dota } \\
\text { de contextos a } \\
\text { agentes; dinamiza, } \\
\text { precipita procesos } \\
\text { de institucionali- } \\
\text { zación }\end{array}$ & $\begin{array}{l}\text { Johan P. Olsen } \\
\text { Elinor Ostrom }\end{array}$ \\
\hline
\end{tabular}

Fuente: Elaboración propia a partir de Vergara (1997), Mackay et al. (2010), Aguiar (2014).

En definitiva, las diferentes versiones del nuevo institucionalismo social e histórico que describieron March y Olsen como reacción a la denominada por ellos mismos «behavioural revolution» de la década de 1960, no privilegian las reglas de juego con las que (supuestamente) se obtienen soluciones de equilibrio (March y Olsen 1984). En su lugar, estos enfoques nos descubren y describen las instituciones y las organizaciones en general como productos desarrollados a partir de luchas entre actores y agentes cuyos recursos son desiguales. Y, en última instancia, sobre estos últimos, solo se pueden proporcionar descripciones plausibles acerca de sus motivaciones y su comportamiento tanto a nivel individual como a nivel colectivo. Pero a ello hay

7. Para una aproximación completa al sentido y utilidad de la encuesta de opinión como método de investigación puede consultarse una de las últimas obras de Font y Pasadas del Amo (2016).

8. La expresión «el ritmo del discurso» fue utilizada por Racionero durante su conferencia en el II. ${ }^{\circ}$ Seminario Público «Ciencia moderna y postmoderna» en la Fundación Juan March el 21 de mayo de 1998. 
que añadir que dichos enfoques también nos procuran argumentos basados en el hallazgo de patrones, razón por la cual la teoría argumental podría integrarse (pues, de facto se hace uso de ella) tanto en los enfoques teóricos del nuevo institucionalismo como en los procesos relacionados con la construcción de sus objetos y resultados de investigación. A todo ello hay que añadir que, sobre el tema de los efectos de la desigualdad en la acción colectiva y el despliegue de la agencia argumentativa, existen resultados de investigación de gran valor relacionados con los modelos de democracia deliberativa, así como suficientes evidencias acerca de que tanto la desigualdad como la lucha por el reconocimiento influyen en los procesos deliberativos que tienen lugar dentro de organizaciones e instituciones. Si traigo a colación estos resultados es para llamar la atención sobre la existencia de una fuerte imbricación -si bien no siempre explícita- de la teoría argumental y el nuevo institucionalismo; una relación que se puede rastrear en la literatura sobre el modelo de la democracia deliberativa y movimientos sociales (Mansbridge 1980; Benhabib 1996; Mouffe 1999; Young 2001; Bang 2003; Kock y Villadsen 2012; della Porta y Rucht 2013). Si las instituciones pueden definirse como hechos sociales persistentes que regulan el comportamiento social, en parte ello se debe a la existencia de modelos de discusión crítica que, a un tiempo, dinamizan y fijan el significado de esos hechos sociales y su poder regulador de la conducta social. Así lo sostenía Paul Ingram cuando afirmaba:

Hay muchas definiciones de institución en sociología. La mayoría se puede subsumir en la siguiente: las instituciones son hechos sociales persistentes que regulan el comportamiento social. «Persistente» indica el rol de las instituciones en la estabilización de la vida social. Los «hechos sociales» capturan la idea de que las instituciones son el producto de la interacción y la asociación, y que existen de manera externa a los individuos. «Regular el comportamiento social» implica que las instituciones sancionan ciertas formas de comportamiento social y desaprueban otras. (Ingram 2007, p. 2353). Traducción mía.

Ingram partía en este fragmento de la definición que dieron March y Olsen de 'institución', según la cual:

Una institución es una colección relativamente duradera de reglas y prácticas organizadas, integradas en estructuras de significado y recursos que son relativamente invariables frente a la rotación de individuos y relativamente resilientes a las preferencias y expectativas de los individuos y las cambiantes circunstancias externas. (March y Olsen 1989). Traducción mía. 


\section{TABLA 4. El nuevo institucionalismo político}

\begin{tabular}{|l|l|l|l|}
\hline \multicolumn{1}{|c|}{ Problemas } & \multicolumn{1}{|c|}{$\begin{array}{c}\text { Ejemplos } \\
\text { de instituciones }\end{array}$} & Capital asociado & \multicolumn{1}{c|}{ Autores/as } \\
\hline $\begin{array}{l}\text { Problema princi- } \\
\text { pal o poderdante } \\
\text { vs agente (i. e. go- } \\
\text { bernantes que ve- } \\
\text { lan por los intere- } \\
\text { ses del principal). }\end{array}$ & $\begin{array}{l}\text { Regle decisión, } \\
\text { sistemas electo- } \\
\text { rales, modelos de } \\
\text { democracia, reglas } \\
\text { de rendición de } \\
\text { cuentas y transpa- } \\
\text { rencia, etc. }\end{array}$ & $\begin{array}{l}\text { Capital político: } \\
\text { informa acerca del } \\
\text { grado de legitimi- } \\
\text { dad de la represen- } \\
\text { tación y el grado } \\
\text { de exigencia de los } \\
\text { principales. }\end{array}$ & $\begin{array}{l}\text { Kenneth Shepsle } \\
\text { William Riker } \\
\text { Fritz Scharpf }\end{array}$ \\
\hline
\end{tabular}

Fuente: Elaboración propia a partir de Vergara (1997), Mackay et al. (2010), Aguiar (2014).

En las últimas dos décadas, bajo la denominación de «nuevo institucionalismo» se han investigado las reglas institucionales formales e informales que estructuran el comportamiento colectivo (Lowndes 2010). Sin embargo, lo relevante aquí es insistir en el hecho de que el nuevo institucionalismo se dice de muchas maneras y ha dado lugar a perspectivas y posiciones teóricas tan sugestivas como potencialmente enfrentadas e incompatibles. Entre dichas perspectivas se cuentan tanto el institucionalismo de la teoría de la elección racional, como el institucionalismo histórico, así como el institucionalismo organizacional (también llamado sociológico) y el institucionalismo discursivo (de índole constructivista).

Todo lo anterior me lleva por consiguiente a sostener en estas páginas que, en primer lugar, y siguiendo a Racionero tanto el nuevo institucionalismo social como el histórico y el discursivo o constructivista, constituyen programas especialmente adecuados para investigar las prácticas argumentativas que intervienen tanto en los procesos de construcción e intercambio sociales de sentido como en la interpretación de los mensajes conforme a los archivos generados por la memoria histórica (1); y, junto a esto y en segundo lugar, que el enfoque socio-institucional debería entenderse principalmente como un programa de investigación destinado a interpretar procesos de la esfera pública que actúan como un mecanismo de cálculo y conformación de capital social por lo que será necesario examinar críticamente el empleo de las

9. Para un análisis de los distintos modelos y metodologías del nuevo institucionalismo pueden consultarse los trabajos de Mackay, Kenny y Chappel (2010), el volumen colectivo editado por James Mahoney y Kathleen Thelen (2010) o el libro editado por Xosé Carlos Arias y Gonzalo Caballero (2014). 
metáforas relacionadas con dicho cálculo a fin de proponer la que mejor se ajuste a este segundo argumento (2). De la fuerza suasoria de la siguiente argumentación múltiple depende la relevancia de esta posible aportación programática al campo de la teoría argumental en su relación con los desarrollos del nuevo institucionalismo.

\section{TABLa 5. El nuevo institucionalismo discursivo o constructivista}

\begin{tabular}{|c|c|c|c|}
\hline Problemas & $\begin{array}{c}\text { Ejemplos } \\
\text { de instituciones }\end{array}$ & Capital asociado & Autores/as \\
\hline $\begin{array}{l}\text { La influencia de } \\
\text { los discursos y las } \\
\text { ideas sobre pre- } \\
\text { ferencias y pro- } \\
\text { puestas, y el com- } \\
\text { portamiento de } \\
\text { actores, así como } \\
\text { su interacción. }\end{array}$ & $\begin{array}{l}\text { Discursos, ideas, } \\
\text { motivaciones, } \\
\text { contextos de la } \\
\text { acción, elementos } \\
\text { ideacionales, na- } \\
\text { rrativas, estrate- } \\
\text { gias, etc. }\end{array}$ & $\begin{array}{l}\text { Capital discursivo: } \\
\text { refuerza la habi- } \\
\text { lidad de actores } \\
\text { para construir } \\
\text { contextos de } \\
\text { justificación de } \\
\text { ideas, argumentos } \\
\text { y motivos para la } \\
\text { acción. }\end{array}$ & $\begin{array}{l}\text { John L. Campbell } \\
\text { Ove K. Pedersen } \\
\text { Vivien Schmidt } \\
\text { Fiona Mackay }\end{array}$ \\
\hline
\end{tabular}

Fuente: Elaboración propia a partir de Vergara (1997), Mackay et al. (2010), Aguiar (2014).

\section{El PRINCIPIO DE DIRECCIÓN DE ADECUACIÓN}

De acuerdo con la perspectiva socio-institucional defendida por Vega el discurso público se concentra en el debate construido a través de la discusión de propuestas y la ponderación de alternativas entre agentes argumentativos. La existencia de un marco institucional del debate garantiza el buen desarrollo de dichas ponderaciones y, en general, aporta reglas discursivas y procedimentales al debate público. La deliberación sería, de acuerdo con esta concepción, un caso ilustrativo de interacción argumentativa en el amplio ámbito de lo social. Por consiguiente, la deliberación que tiene lugar en dichos entornos de debate es de tipo colectivo y, por así decir, tiene un sujeto plural (Navarro 2018). La interacción argumentativa entre agentes es el fenómeno empírico que más atención merece entre los partidarios del enfoque socio-institucional. La razón de que así sea se debe a que dicha interacción tiene el poder de conformar procedimentalmente y nutrir de propuestas el proceso deliberativo en cuanto tal. 
Entiendo por deliberación en este contexto una interacción argumentativa entre agentes que tratan, gestionan y ponderan información, opciones y preferencias, en orden a tomar de modo responsable y reflexivo una decisión o resolución práctica sobre un asunto de interés común y debatible, al menos en principio, mediante los recursos del discurso público, p. ej., mediante razones comunicables y compatibles más allá de los dominios personales o puramente profesionales de argumentación. (Vega 2013, p. 121).

Ciertamente, la balanza de la razón de Leibniz que subyace a esta definición es la imagen que mejor representa la confrontación interpersonal precisamente porque en ella se expresa y retiene visualmente una versión normativa (de ese modelo) de interacción. Muchos especialistas han utilizado la imagen de la balanza de Leibniz como metáfora de las reglas discursivas y los principios procedimentales que permiten a los agentes efectuar ponderaciones razonables, transparentes y públicas. La concepción socio-institucional de la argumentación que sostienen tanto Vega como van Eemeren se enfoca casi exclusivamente en el fenómeno de la confrontación y la interacción discursivas. Como resultado de ello, la imagen final que se utiliza paga el precio de un cierto aislamiento ya que existe un importante fenómeno difícilmente subsumible en esa metáfora. Me refiero al fenómeno de la agencia, el cual dota de sentido a todo intercambio dialéctico en la medida en que los agentes exhiben un determinado comportamiento argumentativo. Este mismo fenómeno se ha puesto de manifiesto en los estudios acerca de la democracia deliberativa pues no son pocos los autores que llaman nuestra atención acerca de la importante dimensión de los análisis sobre comportamiento deliberativo: un problema de investigación asociado con la psicología política, en cuyo reconocimiento han influido tanto periodos de atención declarada como de falta de seguimiento en la historia de los estudios sobre teoría de la demo$\operatorname{cracia}^{10}$.

Para entender de un modo más certero en qué consisten las prácticas argumentativas es necesario sustituir la imagen de la balanza de la razón de Leibniz por la imagen de la lista de la compra propuesta por Anscombe (1957) en su conocida obra Intention. Una lista de la compra puede verse en la dirección mundo-mente cuando la usamos para ir rellenando el carro de la

10. Este es el planteamiento que subyace por ejemplo a los trabajos presentados por Angelica Vetter y Brigite Geissel, en el panel «Deliberative Behavior» presentado por Marina Lindell y Julia Jennstål en el congreso internacional promovido en 2017 por European Consortium for Political Research en la Universidad de Oslo. 
compra. Pero la misma lista de la compra puede verse en la dirección mentemundo cuando comprobamos que lo que habíamos listado (lo que teníamos en mente comprar) ya está dentro del carrito. En el primer caso, el mundo es transformado para adecuarse a la intención. En el segundo, la intención debe adecuarse al mundo para ser verdadera. La agencia es por consiguiente una clase de «capacidad» porque mediante ella los seres humanos $-\mathrm{y}$ especialmente los agentes argumentativos, como haré ver a continuación- controlan intencionalmente una parcela de la realidad. Esta compleja capacidad entraña una coordinación de facultades y habilidades puesto que lo que (a través de ella) se exige es el despliegue de una cierta relación entre intención y resultados.

El conocimiento de la agencia (a diferencia del conocimiento teórico) es un tipo de conocimiento de ajuste mundo-mente. Anscombe utilizó dicha imagen (i.e. la lista de la compra) con el propósito de ilustrar el «principio de dirección de adecuación» que aquí denominaré el quinto principio porque -de acuerdo con nuestro argumento- amplía la perspectiva de la lógica civil. De acuerdo con dicho principio, la relación de agencia es una relación causal entre una intuición y una conducta que resulta de un fin. Es esta imagen y no la de la balanza -la cual remite a la operación cognitiva de ponderar- la que nos alerta sobre la existencia de un contexto de la acción. El contexto de la acción constituye un auténtico factor institucional porque es él, y no el mecanismo de la balanza, el que, en cada caso, nos informa acerca de las reglas, las normas interiorizadas, las prescripciones compartidas (sean estas formales y/o informales), las convenciones, etc. Lo realmente vinculante para determinados agentes argumentativos son los contextos sociales de los que extraen el tipo de información aludida, y que remiten a aquellos factores que se deben en cada caso seleccionar para llevar a efecto el diseño y la modulación del comportamiento argumentativo si de verdad se desean alcanzar determinados fines. Para decirlo de una manera sumaria: el agente argumentativo encuentra en el contexto social la información necesaria acerca del tipo de relación causal entre una intuición (e. g. creencia, propuesta, preferencia) y la conducta argumentativa que mejor satisfaga, en cada caso, sus objetivos como proponente u oponente. El carácter social de dicha agencia argumentativa no es por consiguiente el resultado de la suma de las capacidades - mucho menos del conocimiento- de individuos que estén en la posición de poder proponer argumentos y/o en la de mostrar su oposición en contrarréplicas. En lo que se refiere al carácter individualizado de dichas expresiones y el aparente protagonismo de sus agentes, cabe esgrimir 
los argumentos presentados por Steve Fuller para refutar la visión analítica de la epistemología social de autores como Alvin Goldman, a saber, que los individuos adquieren sus «identidades epistémicas»-sus respectivas agencias argumentativas, añadimos aquí- en formas y términos que ya existían previamente en un determinado conocimiento social (e. g. bien como vencedores dialécticos o discursivos, bien como oponentes, cuando no como revisores de creencias ampliamente admitidas, o innovadores agentes argumentativos, etc.). Estas afirmaciones están implícitas en el esbozo de Racionero toda vez que la teoría argumental no puede desligarse de la perspectiva hermenéutica. La práctica argumental está ligada a la práctica de interpretar los mensajes de acuerdo con los archivos generados por la memoria histórica entre ellos se incluyen los archivos relativos a la agencia argumental acaecida, esto es, a la memoria de sus logros o fracasos, al posible rechazo generado o, por el contrario, a la adhesión y legitimidad adquiridas. Los efectos de la práctica argumental y su agencia actúan sobre esos archivos de la memoria, sobre sus repertorios y tópicos, pero también extraen rendimientos característicos y logros colectivos que no solo cabe caracterizar desde el punto de vista de la lógica, la retórica y la dialéctica, ya que -conforme a Racionero- el campo argumental forma parte de un proyecto de naturalización para el estudio de la racionalidad en su conjunto y debe incluir la pragmática, la semiología y la hermenéutica.

Lo que subrayo aquí es que la interacción y la práctica argumentativas solo son el resultado del despliegue de una determinada agencia en un contexto de la acción colectiva. La agencia argumentativa y el denominado «factor institucional» garantizan la emergencia de una práctica socialmente establecida como, por ejemplo, la práctica comunicativa de dar y pedir razones. La capacidad que posee un agente individual o colectivo para actuar en un mundo (i.e. agencia) está estrechamente relacionada con el contexto social (i.e. factor institucional). Ahora se entenderá mucho mejor por qué van Eemeren extrajo de todo ello el importante corolario al que me he referido aquí en los siguientes términos:

Corolario-La práctica comunicativa de argumentar, y de argumentar estratégicamente, no solo está determinada por precondiciones institucionales, sino que dicha práctica es un efecto derivado de la existencia de dichas constricciones institucionales. 
A partir de este hallazgo, y para poder proseguir con un proyecto de marcado carácter normativo, van Eemeren decidió asumir las tesis del institucionalismo de elección racional, y partió por consiguiente del supuesto de que las instituciones permiten reducir la incertidumbre con respecto a la conducta ajena. Los teóricos de la elección racional acentúan la naturaleza calculadora de los agentes racionales; es decir, que asumen la existencia de reglas entendidas como constricciones externas de la decisión racional ${ }^{11}$. De este tipo son por ejemplo las reglas procedimentales que rigen una discusión crítica según la teoría pragma-dialéctica de la argumentación defendida por van Eemeren. No es tan claro sin embargo qué modelo de institucionalismo es el que asume Vega cuando este propone una interpretación normativa de la perspectiva socio-institucional (Marraud 2015, 170). El institucionalismo sociológico que explica el surgimiento de normas y convenciones -en numerosas ocasiones admitidas acríticamente, esto es, como si fueran algo dado por parte de los especialistas del campo argumental- constituye una perspectiva mucho más acertada para detectar aquella dimensión cognoscitiva y simbólica de la que los agentes argumentativos extraen guiones, categorías y modelos indispensables para la interacción argumentativa. Por consiguiente, la perspectiva sociológica aplicada al campo argumental nos descubre un tipo de investigación histórico-social de extrema importancia. De acuerdo con dicha perspectiva, se deberían rastrear guiones, categorías, modelos, esquemas, etc.; pues los actores sociales -una categoría que incluye el perfil y rol de agentes argumentativos, entre otros posibles- crean reglas y procedimientos que, a su vez, les crean a ellos.

Una pregunta que debemos por consiguiente formularnos es la de si estamos dispuestos a pagar el precio de una indagación sociológica que ponga el acento en el aspecto social y cultural. Una perspectiva así podría conducir a los especialistas del campo argumental a la necesidad de matizar sustancialmente

11. En la perspectiva institucionalista inspirada en la teoría de la elección racional se asume el individualismo metodológico cuando esta explica el problema de la argumentación como un fenómeno ciertamente social pero susceptible de análisis a partir de los individuos y del conjunto de hipótesis que cabe establecer sobre ellos para explicar su conducta. Es solo a partir de la asunción del modelo institucionalista de elección racional como cabe entender la dimensión normativa de concepciones de la argumentación como la defendida por la Escuela de argumentación de Ámsterdam. Para un análisis en profundidad de la teoría de la elección racional, de su índole normativa cuando "proporciona imperativos condicionales sobre los medios más adecuados para alcanzar determinados fines» puede consultarse La razón desencantada. Un acercamiento a la teoría de la elección racional de Elisabetta Di Castro (2002). 
cuando no renunciar directamente a la (uniformadora) empresa de fundamentación normativa. El planteamiento de esta cuestión es permanente en los estudios sobre democracia deliberativa. En los últimos años, la tendencia a valorar el impacto que los aspectos sociales, políticos, económicos, culturales e incluso identitarios y emocionales tienen sobre la dinámica y el comportamiento deliberativos es mucho mayor que la tendencia a reivindicar la universalidad de principios y normas (Sass y Dryzek 2014; della Porta y Rucht 2013; Urfalino 2016; Murguía Lores 2016). Hemos visto que la versión del institucionalismo de elección racional que asume van Eemeren constituye un poderoso instrumento teórico que, pese a no haber sido desarrollado plenamente en su obra, tiene el poder de legitimar y dotar de coherencia su modelo normativo de la dialéctica (van Eemeren 2010, 2011; Navarro 2015a). Pero también podría afirmarse que su orientación institucionalista basada en la teoría de la elección racional impide -o al menos convierte en una tarea más difícil- el objetivo de detectar procesos de un marcado carácter dinámico. Me refiero con ello al tipo de procesos que emergen cuando un investigador asume que las precondiciones institucionales no prevalecen íntegramente en la práctica comunicativa pues los agentes argumentativos no reproducen de manera autómata ni los guiones ni las categorías ni los modelos, ni tampoco los esquemas argumentativos que cabe asociar a cada marco institucional de debate. El fin último de las estrategias argumentativas no es el de preservar o hacer cumplir guiones o categorías específicas de dominios profesionales de la argumentación. Del mismo modo, podría decirse que el objetivo del hablante que profiere una sentencia no es defender la gramática de su lengua -si bien es cierto que la supervivencia de una lengua puede estar en peligro si esta no cuenta con hablantes.

La imagen de la lista y el carrito de la compra describe mucho mejor el modelo de agencia que encontramos en los entornos deliberativos. El comportamiento deliberativo de los agentes es racional cuando se produce cierta relación causal entre una creencia (que se manifiesta y articula en un conjunto de propuestas y preferencias) y una conducta argumentativa que resulta en un fin (e. g. la selección de estrategias argumentativas que maximicen sus resultados dialécticos o retóricos, y se adapten mejor al contexto; un comportamiento deliberativo consecuente, etc.). La imagen de la balanza de la razón describe bien la perspectiva socio-institucional en los casos en los que un especialista del campo de la argumentación desea destacar rasgos como el reconocimiento de una cuestión de interés público y pendiente de resolución, la existencia de propuestas o la necesidad colectiva de inducir un logro consensuado porque este destaca por su interés general. Sin embargo, los rasgos a los que acabo de aludir solo describen la vinculación (normativa) de 
la deliberación con la razón práctica. Son por tanto rasgos insensibles a las condiciones y características del comportamiento deliberativo tanto individual como colectivo, el cual es producto de la agencia argumentativa.

Los esquemas argumentativos conductivos que se seleccionan para describir las fases pragmáticas y conversacionales del entendimiento y la cognición social adolecen de un intelectualismo extremo. Al escribir esto me refiero a las fases de la deliberación cuya existencia admiten la mayoría de los especialistas a partir del trabajo del que son coautores Hitchcock, McBurney y Parsons (2001), a saber: planteamiento del problema y apertura; distribución de la información; avance de propuestas y contrapropuestas; ajustes, revisiones; resolución, etc. Entre otros aspectos, este modelo de esquema argumentativo conductivo -porque aparece bajo la forma de una lista de «pros» y «contras» destinada a ofrecer razones para creer algo y para aceptar, llegado el caso, una conclusión- no nos permite identificar con facilidad ni las fases que se despliegan realmente en el contexto sociopolítico ni los elementos retóricos e ideológicos relacionados con la apertura y producción de procesos de legitimidad y reconocimiento (Navarro 2011). Parece razonable afirmar que ni la legitimidad ni el reconocimiento pueden asumirse sin más como si fueran dos variables dependientes de las fases de la deliberación descritas anteriormente. Los agentes argumentativos protagonizan debates públicos en busca de legitimidad y reconocimiento; pero no hay normas ni esquemas argumentativos cuyo empleo garantice el éxito de manera automática. Precisamente por ese motivo la práctica argumental no se constituye con independencia ni de la agencia argumentativa ni de los efectos institucionales que aquella llegue a producir en cada caso. Los agentes utilizan esquemas argumentativos conductivos para obtener rendimientos intelectuales y capitales simbólicos complejos cuya producción y circulación no garantiza sin embargo la sola construcción lógica de argumentos. A través de la deliberación pública, la racionalidad colectiva pone en juego la agencia argumentativa y vehicula procesos de producción de legitimidad y reconocimiento. Estas dos funciones o cualidades de la agencia argumentativa tienen, a su vez, una estrecha relación con la producción de capital social y cultural en un determinado contexto social. 


\section{A MODO DE CONCLUSIÓN}

Una de las variables que influye en la configuración sociopolítica del comportamiento deliberativo de los agentes argumentativos es la percepción que estos tienen acerca de los riesgos derivados de la participación. Dichos riesgos van más allá tanto de los logros como de las frustraciones asociadas a las resoluciones obtenidas. A pesar de ello $-y$ tal vez como consecuencia de que, de hecho, la resolución sea percibida como una de las fases de la deliberación-, suele asumirse que las resoluciones son el tipo de resultado que se puede alcanzar a través de procesos deliberativos. Sin embargo, tal y como aquí sostengo -aun cuando así sea percibido por los agentes que conforman determinadas culturas de la deliberación-, las resoluciones no son ni el único resultado deseable ni el único resultado que de hecho se obtiene al finalizar un debate público. La adquisición de capital social y simbólico es uno de los resultados más importantes, y se persigue de facto como un fin en sí mismo por parte de los distintos agentes argumentativos. Existen resoluciones consensuadas que se alcanzan colectivamente y que son del interés de algunos individuos o incluso de todo el grupo en su conjunto pues la agencia argumentativa puede asumirse desde parámetros institucionales tales como la cooperación y colaboración intelectuales. Sin embargo, y de manera paradójica, una resolución favorable para un individuo o un colectivo puede conllevar, en numerosas ocasiones, la pérdida de reputación o incluso de legitimidad frente a otros grupos sociales o colectivos. La reputación y la legitimidad forman parte del capital social que nos identifica como individuos y como colectivos. Es un tipo de capital que nunca permanece intacto al finalizar cualquier proceso deliberativo. Este hecho lo convierte en una variable importante para tener en cuenta en la toma de decisiones de agentes argumentativos a la hora de decidir, por ejemplo, cómo, cuándo y por qué es de su interés formar parte de un intercambio argumentativo. Cuando se delibera en un entramado institucional cada agente argumentativo calcula y determina el tipo de beneficio y/o pérdida de capital social y capital político derivado de su agencia y comportamiento argumentativos. Incluso las fases de la deliberación no tienen sentido en sí mismas -ni desde un punto de vista lógico ni desde un punto de vista dialéctico y retórico- si no se asume este punto de partida cuya sintonía con el modelo institucional de la elección racional resulta evidente. Uno de los factores que dota de sentido a las fases de la argumentación es la simple existencia de expectativas; pero sin olvidar el importante factor de la permanente acción sancionadora de las instituciones 
que regulan el comportamiento social de agentes argumentativos. Es este último factor el que muestra un peso específico de mayor gravedad: anuncia una dimensión de lo social cuyo entramado se reserva para sí tanto la duración como la permanencia en el tiempo de las relaciones biyectivas que lo conforman. Porque las instituciones influyen sobre el cálculo y el posterior aumento o pérdida de capital sociopolítico; sí, es cierto, pero, al mismo tiempo, el comportamiento deliberativo seleccionado por el agente tiene un impacto sobre el entramado institucional. Por eso, puede decirse que el nuevo institucionalismo social o sociológico proyecta a la teoría argumental hacia derroteros que van más allá de la conformación de propuestas o la identificación de preferencias en que suele encallar la teoría argumental inspirada en el individualismo metodológico.

\section{Agradecimientos}

Este trabajo forma parte de los desarrollos de dos proyectos «El desván de la razón: cultivo de las pasiones, identidades éticas y sociedades digitales» (PAIDESOC) [FFI2017-82535-P], del que soy Investigadora Principal 2 y del proyecto «Democracia deliberativa y capital social en contextos interculturales» [CAS18/00351], desarrollado en University of Oxford.

\section{REFERENCIAS BIBLIOGRÁFICAS}

Aguiar, F. (2014). «Análisis institucional y decisiones imparciales» en Arias, X. y Caballero, G. (eds.) Nuevo institucionalismo: gobernanza, economía y politicas públicas. Madrid. Centro de Investigaciones Sociológicas, pp. 231-245.

Anscombe, E. (1958). Intention. Oxford. Basil Blackwell.

Arias, X. C. y G. Caballero (eds.) (2014). Nuevo institucionalismo: gobernanza, economía y políticas públicas. Madrid. Centro de Investigaciones Sociológicas.

Navarro, M. ${ }^{a}$ G. (2011). «Controversy and Confrontation» Informal Logic 31(1), 7, pp. 69-74.

Navarro, M. ${ }^{a}$ G. (2015a). «El lugar de la controversia en la argumentación» En Fernando Leal Carretero (coord.). Argumentación y pragma-dialéctica: Estudios en honor a Frans van Eemeren. Guadalajara (México): Editorial Universitaria.

NAvarro, M. ${ }^{a}$ G. (2015b). «Consensuar y disentir en un modelo de democracia contestataria» Revista de Filosofía Conceptos vol. 4, núm. 8, pp. 110-127. 
Navarro, M. ${ }^{a}$ G. (2015c). «El rol de las heurísticas sociales en la deliberación» Bajo Palabra. Revista de filosofía núm. 10, pp. 123-134.

Navarro, M. ${ }^{a}$ G. (2018). «A Defense of Cooperativa Cognition and Its Rationality» In Concha Roldán, Daniel Brauer and Johannes Rohbeck (eds.) Philosophy of Globalization. Berlin: De Gruyter, pp. 33-46.

BANG, H. P. (2003). Governance as Social and Political Communication. Manchester. Manchester University Press.

Benhabib, S. (ed.) (1996). Democracy and Difference. Contesting Boundaries of the Political. Princeton. Princeton University Press.

Bermejo Luque, L. (2010). «Encuesta. El estado actual de los estudios sobre Argumentación». Revista Iberoamericana de Argumentación 1, pp. 1-36.

COASE, R. (1937). «The Nature of the Firm». Economica 4(16), pp. 386-405.

Della Porta, D. y D. Rucht (2013). Meeting Democracy. Power and Deliberation in Global Justice Movements. Cambridge. Cambridge University Press.

Di Castro, E. (2002). La razón desencantada. Un acercamiento a la teoría de la elección racional. México: Universidad Nacional Autónoma de México. Instituto de Investigaciones Filosóficas ( $2^{\mathrm{a}}$ ed. 2009).

Eemeren, F. H. van (2011). «In Context. Giving Contextualization its Rightful Place in the Study of Argumentation», Argumentation 25, pp. 141-161.

Eemeren, F. H. van y Grootendorst, R. (1984). Speech Acts in Argumentative Discussions. A Theoretical Model for the Analysis of Discussions Directed towards Solving Conflicts of Opinion. Berlin. De Gruyter.

Eemeren, F. H. van (2010). Strategic Maneuvering in Argumentative Discourse: Extending the Pragma-dialectical Theory of Argumentation. Amsterdam/Philadelphia. John Benjamins Publishing Company.

Font, J. y S. Pasadas del Amo (2016). Las encuestas de opinión. Madrid. Los libros de la Catarata.

Garssen, B. (2012). «Introduction to the Special Issue: Twenty-five years of Speech Acts in Argumentative Discussions». Cogency vol. 2, núm. 1, pp. 13-21.

Hitchcock, D., P.McBurney y S. Parsons (2001). «A framework for deliberation dialogues». Proceedings of the 4th Biennial Conference OSSA, Ontario.

Ingram, P. (2007). «Institutionalism», en: Ritzer, G. (ed.) The Blackwell Encyclopedia of Sociology. Oxford. Blackwell Publishing, pp. 2353-2357.

Kоск Ch. y L. Villadsen (2012). Rhetorical Citizenship and Public Deliberation. Pennsylvania. The Pennsylvania State University.

LownDES, V. (2010). «The institutional approach», en: Marsh, D. y Stoker, G. (eds.) Theories and Methods in Political Science, $3^{\text {rd }}$ edn. Basingstoke. Palgrave Macmillan.

Mackay, F., M. Kenny y L. Chappel (2010). «New Institutionalism Through a Gender Lens: Towards a Feminist Institutionalism?». International Political Science Review 31(5) pp. 573-588. 
Mahoney, J. y K. Thelen (eds.) (2010). Explaining Institutional Change. Cambridge. Cambridge University Press.

Mansbridge, J. J. (2010). Beyond Adversary Democracy. New York. Basic Books.

March, J. y J. P. Olsen (1984). «The New Institutionalism: Organizational Factors in Political Life». The American Political Science Review 78(2), pp. 734-749.

Marraud, H. (2015). «La lógica del discurso civil», en: Hubert Marraud y Paula Olmos (eds.), De la demostración a la argumentación. Ensayos en bonor de Luis Vega, Madrid. Servicio de Publicaciones de la Universidad Autónoma de Madrid, pp. 163-177.

Mouffe, Ch. (1999). «Deliberative Democracy or Agonistic Pluralism?». Social Research 66, pp. 745-758.

Murguía Lores, A. (2016). «Injusticias epistémicas y teoría social». Dilemata. International Journal of Applied Ethics 22, 1-19.

NorTH, D. C. (1990). Institutions, institutional change and performance. New York. Cambridge University Press.

Putnam, R. D. (1993). Making Democracy Work. Civic Traditions in Modern Italy. Princeton. Princeton University Press.

Racionero, Q. (2000a). «La resistible ascensión de Alan Sokal. (Reflexiones en torno a la responsabilidad comunicativa, el relativismo epistemológico y la postmodernidad.)». ÉNDOXA: Series Filosóficas 12, pp. 423-483.

Racionero, Q. (2000b). «El escupitajo de luna o esmeralda de los filósofos. Algunas notas más sobre ciencia moderna postmoderna». ÉNDOXA: Series Filosóficas 13, pp. 55-84.

Racionero, Q. (2009). «La controversia de nación e Imperio. Reacción de los pensadores españoles a la Revolución de Holanda (I)». INGENIUM. Revista de bistoria del pensamiento moderno 2, pp. 24-52.

Racionero, Q. (2010a). "La controversia de nación e Imperio. Reacción de los pensadores españoles a la Revolución de Holanda (II)». INGENIUM. Revista de bistoria del pensamiento moderno 3, pp. 94-118.

Racionero, Q. (2010b). «Encuesta: El estado actual de los estudios sobre Argumentación». Revista Iberoamericana de Argumentación 1, pp. 30-32.

SAss, J. y J. S. Dryzek (2014). «Deliberative Cultures», Political Science 42(1), pp. 3-25.

Urfalino, Ph. (2013). Cerrar la deliberación. Teoría de la decisión colectiva. Buenos Aires. Prometeo Libros.

VEGA, L. (2004). «De la lógica académica a la lógica civil: una proposición». Isegoría. Revista de filosofía moral y política 31, pp. 131-149.

VEGA, L. (2008). «Deliberación y discurso civil: nuevas perspectivas en el campo de la argumentación». Revista Laguna 22, pp. 35-51.

VegA, L. (2012), "Vindicación y elogio de la retórica». Revista Iberoamericana de Argumentación 5, pp. 1-18. 
Vega, L. (2013a). La fauna de las falacias. Madrid. Trotta, pp. 119-128.

VEGA, L. (2013b). "La deliberación: un campo de prueba del discurso público”, en Adrán Grimate-Welsh y Julieta Haidar (eds.) Argumentación. México, UAMIztapalapa, pp. 123-152.

VeGA, L. (2013c). «Argumentando una innovación». Revista Iberoamericana de Argumentación 7, pp. 1-17.

VegA, L. (2016). «Variaciones sobre la deliberación». Dilemata. Revista Internacional de Éticas Aplicadas 22, pp. 203-220.

VERGARA, R. (1997). «Estudio introductorio», en March, J. y Olsen, J. El redescubrimiento de las instituciones. La base organizativa de la política. México. Fondo de Cultura Económica, pp. 9-40.

Wenzel, J. W. (1990). "Three Perspectives on Argument. Rhetoric, Dialectic and Logic», en: Robert Trapp y Schuetz, Janice (eds.) Perspectives on Argumentation: Essays in Honor of Wayne Brockriede. New York. Idebate Press, pp. 9-26.

Williamson, O. E. (1985). The Economic Institutions of Capitalism. Chicago. The Free Press.

Young, I. M. (2001). «Activist challenges to deliberative democracy». Political Theory 29(5), pp. 670-690. 